\title{
Nietzsche, clínica e autogenealogia: um movimento de intercessão entre Nietzsche e o modelo clínico da modernidade
}

\author{
Nietzsche, clinic and autogenealogy: an intercession motion between Nietzsche \\ and modernity's clinical model
}

\author{
Yan Menezes Oliveira; Karina Acosta Camargo \\ Universidade Federal do Espírito Santo; Pontíficia Universidade Católica de São Paulo
}

\section{RESUMO:}

O presente trabalho intenta apontar um movimento de intercessão entre o pensamento de Friedrich Nietzsche e a atividade clínica. Tal aproximação e troca se justifica tanto em função da singular interpretação do filósofo a respeito do sofrimento e do adoecimento ao longo de sua obra, quanto de sua aproximação da atividade clínica quando este busca diagnosticar e transformar diversos aspectos considerados doentes na modernidade. Apresentou-se uma crítica genealógica da emergência dos valores do modelo clínico da modernidade, buscando identificar expressões da "vontade de verdade" em tal modelo em contraposição ao pensamento de Nietzsche. Propôs-se, então, pesquisar na obra de Nietzsche e de comentadores alguns conceitos, tais como grande razão, grande saúde, eterno retorno, transvaloração de todos os valores e autogenealogia, que corroborassem com a produção de um modelo clínico distante de preconceitos morais. Conclui-se relevante e possível indicar um movimento de intercessão entre o pensamento de Nietzsche e a atividade clínica.

Palavras-chave: Nietzsche; clínica; autogenealogia

\begin{abstract}
:
This paper aims to point out a intercession motion from Friedrich Nietzsche's towards clinical activity. This approximation and exchange is justified both in terms of the philosopher's unique interpretation of suffering and illness throughout his work, as of his approach to clinical activity when he seeks to diagnose and transform various aspects considered ill in modernity. A genealogical critique of the emergence of the values of the modernity's clinical model was presented, seeking to identify expressions of the "will to truth" in such a model in opposition to Nietzsche's thought. It was proposed to research in the work of Nietzsche and commentators concepts such as great reason, great health, eternal return, transvaluation of all values, and autogenealogy, which corroborate with the production of a distant clinical model of moral prejudices. It is concluded that it is relevant and possible to indicate a intercession motion from Nietzsche's towards the clinical activity.
\end{abstract}

Key-words: Nietzsche; clinic; autogenealogy

DOI: 10.12957/mnemosine.2020.57671 


\section{Um movimento de intercessão: Nietzsche e a saúde}

Grosso modo, o principal objetivo deste trabalho é indicar um movimento de intercessão entre o pensamento de Friedrich Nietzsche e a atividade clínica, em especial no que tange à clínica psicológica. Por movimento de intercessão compreendemos, com Gilles Deleuze (1992), um movimento onde o pensamento produz certo deslocamento, certa diferenciação de si no encontro e na interferência de saberes e disciplinas aparentemente distantes e distintos, tais como a filosofia, a literatura e a prática clínica. Tal movimento de intercessão a ser criado entre a filosofia deste pensador germânico do século XIX e um modelo clínico medicinal, que emerge ao longo da modernidade europeia, nos pareceu extremamente promissor, tendo em vista as vastas contribuições e distanciamentos nietzschianos para se pensar a vida e a experiência do sofrimento nela existente dentro de uma perspectiva trágica.

O referido modelo clínico medicinal moderno, que se destrinchou e influenciou especialidades clínicas responsáveis pelo cuidado da saúde compreendida como mental, parece afetar o filósofo como problema de seu tempo. Nietzsche se coloca, mesmo que de maneira a fazer uma torção do termo, como "médico filósofo" (GC, Prólogo, §2), as tarefas de compreensão e transformação do sofrimento e da doença, buscando perspectivar afetos decorrentes da experiência da saúde e da doença, sua organização em signos identificáveis e a modificação de sua organização dentro da existência. Ao mesmo tempo, o pensamento nietzschiano se distanciaria tanto de certas premissas, noções e conceitos do modelo clínico da modernidade no que diz respeito ao tema do sofrimento, que precisamos especificar e trabalhar analiticamente de que forma esse movimento de intercessão seria possível de ser construído, e de que forma poderia influenciar hoje a produção de subjetividade em relação à produção da saúde.

$\mathrm{O}$ artigo intenta relacionar a crítica nietzschiana a certa tradição ocidental do pensamento, que elegeu e perpetuou o valor da verdade como acima dos outros valores, ao problema do modelo de produção de saúde que essa tradição do pensamento foi capaz de produzir e nos influencia contemporaneamente. Trazendo o valor e sentido histórico da produção de verdade pelos homens, Nietzsche (GM, III, §24) indaga sobre por quê e quem (filósofo, cientista, religião, povo) teria precisado eleger como parâmetro ideal e apropriado para a avaliação da vida, em todo seu movimento e exuberância, o parâmetro estático e mortificante que pendula entre o verdadeiro e o falso, entre a verdade e a mentira. 
Seria possível compreender de maneira genealógica, isto é, dentro da compreensão dos fenômenos a partir das "condições e circunstâncias nas quais nasceram, se desenvolveram e se modificaram" (GM, Prólogo 6), que esse parâmetro entre o verdadeiro e o falso não passa de uma forma ruim e adoecida de avaliar e interpretar o mundo, uma vez que não levaria em conta a afirmação do próprio movimento de mudança da vida e buscaria, em realidade, negálo, afirmando, no lugar da vida, preconceitos morais metafísicos e, portanto, imutáveis. Nietzsche, ao criticar a "vontade de verdade" (ABM, §1) de tal tradição do pensamento, transformou o eixo de sua crítica de um parâmetro entre a "verdade" e a "mentira" para o parâmetro entre o que seria "saudável" e "doente", as avaliações e interpretações que afirmariam ou negariam a vida em seus excessos, não apenas no pensamento e na filosofia, mas também nos sistemas morais e em quaisquer formas de produção de valor e sentido.

Acompanhando essa troca de eixo dentro da crítica nietzschiana, o conceito de saúde, bem como o de doença, passaria a se relacionar com o movimento de uma vontade que moveria a vida por meio de suas avaliações e interpretações, afirmando a sua existência, sendo essa vontade nomeada por Nietzsche com a "vontade de poder"1 (ABM, §9). O conceito de doença corresponderia, portanto, a uma forma de vida onde a vontade se voltaria contra a própria vida, se ressentiria das suas experiências e de seus sofrimentos, continuamente imaginando como a própria vida é injusta e como seriam as coisas se tudo se passasse de outra maneira, ou em outro plano (GC, Prefácio, §2). Qualquer forma de avaliação e interpretação da existência, inclusive as adoecidas, como a vontade de verdade, seriam, para Nietzsche, expressão de uma vontade de poder. Assim sendo, até mesmo a doença, como expressão da vontade de poder, pode abrir o espírito para um novo conjunto de valores, a depender de qual exercício da saúde exercitará um corpo.

A partir dessa ligação inicialmente estabelecida entre vontade, saúde, filosofia, moral e as formas de avaliar e interpretar as existências, cabe apontar o pensamento e a metodologia genealógica de Nietzsche, o pensamento que avaliaria histórica e comparativamente o valor dos próprios valores (GM, Prefácio, §6), como integrado à "grande psicologia" (ABM, §23) proposta pelo autor. Tal psicologia seria capaz de avaliar de maneira crítica as transformações históricas das expressões da vontade de poder em um corpo dado. Isto porque tal psicologia não se prenderia aos preconceitos morais vigentes na época do filósofo, mas se apoiaria no agudo perspectivismo do autor e se constituiria como uma "fisio-psicologia" apta a pensar a partir do corpo, dos impulsos, dos afetos e da "grande razão" (Z, I, Dos desprezadores do 
corpo) as transformações da vontade de poder e a saúde dos corpos. Ao mesmo tempo, tal psicologia, por trazer o corpo como a grande razão, percebe a limitação das noções de $e u$ e de consciência como aparatos do conhecimento que defenderiam e justificariam a pequena razão e a vontade de verdade como forças motrizes da compreensão do mundo. Em Nietzsche, o que estaria em jogo, tanto no que diz respeito à sua metodologia filosófica quanto nos parâmetros da avaliação e interpretação da experiência, seria o corpo e sua saúde ao trocar com o mundo.

Por meio da genealogia e da grande psicologia, Nietzsche se aproximaria da leitura dos signos e diagnósticos do adoecimento dentro da cultura, bem como da proposta de transformação e superação desse adoecimento. Seja tomando como objeto de seu diagnóstico e terapêutica todo um sistema moral, como no caso apresentado no livro A genealogia da moral, seja tomando a si mesmo e seu exercício de transvaloração de todos os valores, como exemplificado em Ecce homo, o trabalho de Nietzsche se aproxima de uma atividade clínica e de cuidado que visa transformar a valoração e a interpretação da experiência do sofrimento. A genealogia nietzschiana lê o presente a partir dos signos e sintomas da expressão de uma vontade doente ou sã. Para além do dado no presente, há, para o filósofo, a partir da aguçada leitura sintomática do mal-estar do presente, a possibilidade de se transvalorar os valores atuais em direção não a uma cura do homem, uma vez que o próprio homem com seus valores igualitários e justos seria expressão de uma vontade enfraquecida e adoecida na perspectiva nietzschiana, mas à superação deste. Portanto, a proposta nietzschiana é a superação do modelo centrado no homem, no sujeito ou ainda uma superação dos saberes acerca dele, posto que são tais saberes que o inventam, como diria Foucault em As Palavras e as coisas (1966), inspirado em Nietzsche.

\section{Saúde e modelo clínico na modernidade}

A partir de tais parâmetros genealógicos, pode-se avaliar a emergência e a difusão do modelo clínico da modernidade, contemporâneo ao filósofo, relacionando-o com a vontade de verdade expressa neste modelo, ou seja, sua vontade adoecida que buscaria valores e sentidos definitivos para orientar sua teoria e prática em relação ao sofrimento humano. Pode-se pensar a constituição dos valores do modelo clínico da modernidade e de que maneira, apesar de partilharem de certas ressonâncias, tal modelo seria criticável dentro da perspectiva nietzschiana. Observa-se ao longo da crítica genealógica à moral de Nietzsche a maneira como o ideal ascético, a vontade de verdade e o instinto de rebanho seriam expressões de um 
mesmo espírito de vingança que tenderia a avaliar de maneira negativa a vida e a existência em função do sofrimento que nela existe.

Tal vontade seria responsável pela emergência disso que conhecemos como humano, demasiado humano, em sua constituição ressentida e, portanto, adoecida. A vontade de verdade, que acompanha o homem no seu desdém para com o mundo material e imanente no que ele se apresenta, se expressou nas teorias e práticas clínicas a partir do século XIX implicando uma prática etiológica, sintomatológica e terapêutica que avaliou como negativo o sofrimento em vida, o desequilíbrio do corpo e o desvio da normalidade. Veremos a seguir como as noções de equilíbrio, normalidade e objetividade, bem como a concepção negativa da experiência do sofrimento se perpetuaram como signos da vontade de verdade, como preconceitos morais metafísicos e heranças do modelo clínico nas especialidades que lidariam com o cuidado do sofrimento e do adoecimento, até mesmo no que alcança o sofrimento psíquico e a constituição da subjetividade.

Seria dentro da emergência da anatomoclínica medicinal (FOUCAULT, 2004), emergência essa conjunta às pesquisas laboratoriais em fisiologia experimental e ao crescente controle dos Estados europeus em relação à saúde de suas populações ao longo do século XVIII e XIX, que as noções de equilíbrio, normalidade e objetividade viriam à tona e ganhariam a forma de diretrizes do modelo clínico. A medicina anatomoclínica foi uma das maneiras que a Europa produziu para lidar com o seu sofrimento a partir da perspectiva do conhecimento empírico e científico, em pleno desenvolvimento na época. É ao período de transição do século XVIII para o século XIX que Foucault (2004) atribui a transformação teórica e prática de uma medicina classificatória das espécies para um anatomoclínica dos sinais mórbidos.

A anatomopatologia e sua evolução baseada na observação objetiva do corpo orgânico transformaram a medicina da época e as teorias e práticas de saúde adjacentes, encaminharam a organização e a institucionalização do saber e do fazer médico ao redor da prática clínica e do olhar medicinal objetivo e institucionalmente autorizado. A emergência de tal modelo clínico teria sido acompanhada pela transformação no modelo dos hospitais e das políticas de Estado em relação à saúde dos corpos, que passam a constituir populações. Atrelando-se ao discurso racional da cientificidade, ao saber bioquímico acerca dos microrganismos e aos estudos sobre o equilíbrio do meio interno da fisiologia experimental, a clínica médica passa, 
ao longo do século XIX, a fazer parte de uma transformação política e subjetiva tanto na sociedade europeia como em escala global.

Com a expansão da influência europeia ao redor do globo (FOUCAULT, 2006), através de seu colonialismo e imperialismo do século XIX e início do XX, o referido modelo clínico, seu modo de controle e de produção da verdade sobre o sofrimento teria se alastrado pela Terra como forma hegemônica e autorizada de se lidar com a doença e com o sofrimento. A clínica anamopatológica se especializou, garantindo a posição do médico e da medicina como aqueles que poderiam dizer a respeito do sofrimento orgânico do homem; procurou combater o sofrimento e os desvios em busca da estabilidade e do equilíbrio do corpo fisiológico; colocou o indivíduo em relação a uma população para determinar os parâmetros normais de funcionamento de um corpo e de um povo. Além disso, alegou a demonstrabilidade de sua produção de verdade a respeito da doença e do sofrimento através da noção da objetividade autorizada do olhar médico. Pensando na emergência de uma função-psi e da produção da preocupação acerca da interioridade psíquica dos indivíduos e das populações, é esse modelo clínico que servirá de referência, e também de exigência mínima, para a constituição do saber psiquiátrico e de sua verdade como especialidade médica.

Apesar da prática contínua da psiquiatria através da Europa a partir da virada dos séculos acima mencionados, o poder psiquiátrico apresentou diversas dificuldades em se afirmar como especialidade médica capaz de produzir e dizer a "verdade" sobre o louco e a loucura, principal corpo em torno das questões psiquiátricas na época. Em vários sentidos pode-se observar uma defasagem entre a prática médica, o tratamento moral, e a capacidade de diagnosticar diferencialmente a doença mental e até mesmo apontar a sua causa derradeira. Ao longo do século XIX, o hospital psiquiátrico será, de acordo com os estudos de Foucault (2006), o cenário de uma disputa entre o poder psiquiátrico, investido no corpo do médico, e o corpo dos pacientes, que exigirão que a psiquiatria seja capaz de dizer sobre sua própria verdade. Será um século marcado pela busca da psiquiatria por uma forma de se afirmar como detentora da "verdade" sobre a loucura, a verdade de sua causa, de seus tipos e de sua cura. Parte dessa produção de provas passa pelo inquérito e a anamnese, pelas técnicas da hipnose, pela experiência com a droga e, enfim, pela busca de um lugar no corpo orgânico para diagnosticar e apontar a etiologia da loucura. 
Nesta disputa dentro do espaço asilar europeu, a histérica é a paciente que, ao mesmo tempo, mostrará como a psiquiatria e sua produção institucional da verdade induziu a sua própria doença, e como a causa do seu sofrer não envolve apenas um corpo neurológico, mas também certa sexualidade. Tal episódio traumático para o poder psiquiátrico no final do século XIX acarretaria uma intensa clivagem nesta disciplina que redefiniria os rumos da clínica em relação à psicopatologia e, consequentemente, às suas referências de normalidade psíquica. Por um lado, a psiquiatria rechaçaria a histeria como doença mental e se firmaria nos estudos neurológicos e psicofarmacológicos ao longo do século XX, vertente esta presente até os dias de hoje. Grande parte da clínica psiquiátrica que presenciamos hoje em dia ainda busca a verdade de sua prática no equilíbrio, na normalidade e na objetividade dos exames neuronais, dos manuais de doenças baseados em relações bioquímicas do sistema nervoso e no conjunto de tratamentos farmacológicos.

Por outro lado, ainda sobre as consequências da clivagem da psiquiatria a partir do episódio da histeria, Sigmund Freud, um dos discípulos de Charcot, esboçaria uma clínica das doenças sem causas orgânicas comprovadas. Passaria a desenvolver estudos e técnicas terapêuticas em torno da histeria e da hipnose, inicialmente como neurologista, e progrediria em direção ao tratamento de um outro tipo de sofrimento, a saber, de um sofrimento psíquico, utilizando-se de uma nova técnica clínica, a psicanálise. Reconhecendo os distanciamentos e torções que o exercício psicanalítico opera em relação ao modelo médico, pretende-se estender nossa crítica genealógica do modelo clínico da modernidade até Freud e a emergência da psicanálise, tendo em vista parte da herança do modelo clínico moderno que identificamos como presente na psicanálise, bem como as aproximações das teorias freudianas das de Nietzsche no que diz respeito à psicologia.

Pode-se afirmar que Freud inaugura o debate sobre o sofrimento psíquico junto com a psicanálise. Em seu A interpretação dos sonhos [1900], Freud descreverá um aparelho psíquico como um aparelho majoritariamente inconsciente de memória. Aparelho cujo malestar, cujo sofrimento, se trataria de um sofrimento de matéria mnemônica. Isto é, para Freud, sofre-se das memórias das experiências vividas. A sexualidade apresentada pela histérica ao neurologista e que não cabia mais ser analisada pela psiquiatria passa a ser vista como a energia que movimentaria esse aparelho de lembranças. Seu tratamento através da análise envolveria a recordação, a reavaliação, a reinterpretação, certo reviver e elaborar no presente de um conjunto de memórias relacionadas aos sintomas apresentados pelos pacientes. Freud 
apresenta, de forma ainda mais sistematizada que Nietzsche, uma psicologia para além do órgão da consciência, ciente da importância das faculdades da memória e do esquecimento para a saúde, e uma perspectiva de relação singular entre o sujeito e seu próprio sofrimento.

Apesar das discussões que o próprio Freud levanta a respeito da cientificidade de sua técnica terapêutica, pode-se apontar os limites da psicanálise em relação com o modelo clínico da modernidade, e até com partes do saber psiquiátrico. Retomando as três noções que elencamos como representativas da vontade de verdade dentro do modelo clínico moderno, isto é, equilíbrio, normalidade e objetividade, a teoria psicanalítica continuaria em contato com a noção de equilíbrio quanto aos problemas energéticos do aparelho psíquico que Freud traz, em especial quando este propõe um princípio de constância e uma pulsão de morte (FREUD, [1920]), herdeiras da concepção biológica e fisiológica de busca pelo equilíbrio por parte dos organismos vivos. Freud ainda faria uso da noção de normalidade quando propõe [1900] estruturar toda a psique e toda relação com o sofrimento em torno do problema estrutural do Complexo de Édipo e da sexualidade infantil. E, por fim, por mais que o próprio discurso do paciente seja o material empírico de análise da psicanálise, a interpretação, ou seja, o saber objetivo sobre a experiência do sofrimento e do adoecer, caberia ainda ao psicanalista, especialista na leitura do aparelho psíquico, a leitura das formas de estruturação e dos sinais dos traumas da sexualidade infantil.

Freud continuaria em sua teoria e prática clínica como herdeiro de parte do modelo médico moderno e suas noções de equilíbrio, de normalidade e de objetividade, mesmo que se distanciando e torcendo muitos pontos deste modelo, em especial a definição de normalidade e anormalidade. Foucault é um dos autores que argumenta em direção à continuidade da relação entre a psicanálise e parte da prática clínica da modernidade, tanto em seu História da loucura na Idade Clássica [1961], quanto em seu curso intitulado O poder psiquiátrico [1973-1974], ao apontar como a figura do analista produz um dispositivo de saber-poder pautado na sexualidade e na subjetividade, que dispensaria um conjunto de aparatos e técnicas asilares para ainda assim constituir um aparato que não abriria mão da função-psi, mesmo com a instância do inconsciente, e da compreensão de homem.

Entretanto, fazendo justiça à complexidade da obra de Freud e às suas conexões (declaradas ou não) com as ideias nietzschianas, a abordagem psicanalítica em torno das memórias e das vivências ainda seria um caminho interessante e a ser desenvolvido em conjunto com uma crítica a partir de Nietzsche, tendo especialmente em vista o conjunto de 
técnicas e discussões da clínica psicanalítica no que tange à reinterpretação dos valores e sentidos singulares no exercício de produção de liberdade e autonomia nos corpos através da análise e do entendimento da subjetividade. Além do mais, o trabalho freudiano possui uma estruturação rigorosa e técnica do aparelho inconsciente e de seu manejo na clínica.

Não existe tal estruturação e sistematização a respeito do aparelho inconsciente e seu manejo clínico na obra de Nietzsche, embora exista toda uma discussão acerca da perspectiva afetiva do corpo para se pensar as forças que mobilizam modos de existir em direção ao exercício de uma grande saúde, que discutiremos mais à frente. Mas, de todo modo, não poderíamos dizer que o objetivo do filósofo alemão seria fornecer-nos o mesmo que Freud; talvez, ousaríamos dizer, fornece-nos algo além de Freud. Afinal, a partir de suas ferramentas conceituais que também foram exploradas por Foucault, pudemos criar esse texto crítico acerca tanto da diferença instaurada por Freud no saber médico quanto dos limites da clínica freudiana. Vale a pena ainda ressaltar que a crítica aqui construída relacionando a vontade de verdade e a proposta clínica de Freud se restringiu aos escritos freudianos e não intenta se validar em relação aos escritos de autoras e autores que deram continuidade aos estudos e práticas do médico austríaco.

\section{Nietzsche e uma torção possível do modelo clínico da modernidade}

Ainda no exercício de produção de um movimento de intercessão entre o pensamento de Nietzsche e o modelo clínico da modernidade, nos esforçamos em reunir, pesquisar e analisar aforismos dentro da obra nietzschiana que nos oferecessem material para pensarmos o autor como filósofo capaz de produzir ferramentas conceituais importantes para teorizar e exercer um outro modelo clínico, distante de preconceito morais metafísicos e da vontade de verdade. Para tanto, faz-se indispensável discutir os impactos morais e subjetivos que o ideal ascético, criticado por Nietzsche ao longo de toda sua obra, mas, principalmente, dentro de $A$ genealogia da moral, teria na construção de toda uma tradição que negaria o corpo e produziria o homem como esse ser adoecido de ressentimento para com a própria vida.

Pode-se observar na genealogia da moral realizada por Nietzsche a ligação entre saúde e sistemas morais, bem como a relação doentia entre o existente humano e seu próprio sofrimento. Através de milênios de desenvolvimento de uma moral e uma cultura que valorizaram e interpretaram a vida e o sofrimento presente nesta como algo negativo e necessário de ser evitado, o existente teria acreditado que a vida, como esta se apresenta, não 
valeria a pena ser vivida (GM, III, §23). Entende-se a partir desta genealogia como todas as tentativas morais de curar o homem se constituíram, em realidade, em maneiras de anestesiar e evitar o seu próprio sofrimento através do ressentimento e do espírito de vingança para com a existência.

Nietzsche define o ideal ascético como um sistema moral que contamina a vida e a existência, produzindo o homem como uma existência ressentida. Um sistema moral que, inventando a doença da vida para vender a cura, se expressaria nas artes, nas ciências, na filosofia e, principalmente, nas religiões. Tal ideal teria sido capaz de se apropriar do instinto de rebanho e, ao mesmo tempo, manter o rebanho doente e oferecer o suposto medicamento que curaria as dores em vida (GM, III, §18). Com a infestação da vontade pelo espírito de vingança pregado pelo ideal ascético, a vontade teria perdido sua saúde e sua potência para criar valores e sentidos diante do absurdo da existência e teria passado a desejar o estático, o verdadeiro, o indolor, seja neste mundo ou em além-mundos. Assim sendo, essa forma da vontade de poder, esse modo de vida que se volta contra a própria vida no que ela apresenta de movimento, diferenciação, desvio, se expressaria através da vontade de verdade. Vontade esta que valoraria o certo, o seguro, o estático, o equilibrado e o normativo como valores próximos do bom e do mau, compondo assim as cores do cenário subjetivo de uma suposta humanidade que busca incessantemente a paz e a tranquilidade moral na derradeira verdade, seja sobre o mundo, seja sobre si.

Para Nietzsche, o método genealógico seria capaz de diagnosticar e indicar as causas do adoecimento e a constituição da existência humana pelo seu ressentimento para consigo e com a vida. Diante de tal diagnóstico da cultura ocidental, baseado em seus estudos anteriores, em especial no Nascimento da Tragédia sobre o trágico na Grécia Antiga, movimento de pensamento e de modo de vida que teria avaliado a vida a partir de sua força e de sua exuberância, tendo como principal expressão a figura do Deus Dioniso, Nietzsche teria sido capaz de propor o exercício de transvaloração de todos os valores e, desta maneira, passado a reavaliar a vida de uma perspectiva diferente, a partir de uma interpretação distinta daquela do ideal ascético que compõe o homem como espécie. Com seu vislumbre quanto à força e à afirmação da tragédia grega, o autor seria capaz de pensar a constituição enfraquecida dos valores e dos sentidos da cultura ocidental desde o pensamento racional grego e a sua inversão, sua transvaloração segundo sua perspectiva trágica, libertando a vontade ressentida, vingativa e adoecida do homem em direção à sua própria superação. 
A partir de sua perspectiva trágica, o filósofo é capaz de afirmar o amor fatti, o amor ao destino, como fórmula máxima da afirmação (GC, §276). O amor fatti conseguiria afirmar de maneira trágica o desequilíbrio, as intempéries e até mesmo o sofrimento em vida sem o recurso do ressentimento. Sem se tratar de um otimismo estreito e tacanho, ou mesmo uma mera aceitação da realidade como ela é, o conceito de amor fatti apoia-se numa ética que corta toda a obra nietzschiana e que nega toda a responsabilidade por um agente específico da ação. Tal conceito se conecta com a perspectiva da existência como efeito da própria ação, produzindo-se no movimento com o mundo e arcando com isso que se pode ser.

Aliado ao conceito de amor ao destino, o pensamento do eterno retorno (GC, §341) torna-se um parâmetro ético que orientaria a vida a partir da vida mesma, a partir de cada um dos movimentos e experimentações da vida e sua derradeira e absoluta afirmação em função da força que a própria vida empresta aos corpos. No pensamento do eterno retorno trata-se de um parâmetro ético para a vida, uma vez que cada um dos acontecimentos que perpassam a própria existência deve ser avaliado como acontecimento que se suportaria viver novamente pela eternidade, plantando de maneira hipotética, ao mesmo tempo, o limite do conhecimento da extensão de cada existência, e o limite da avaliação da vida pelo próprio movimento do viver. Através dos conceitos de amor fatti, do pensamento do eterno retorno e do exercício de transvaloração de todos os valores, Nietzsche intenta libertar o corpo e a vontade do espírito de vingança que os teriam assolado por milênios dentro de nosso sistema moral e, desta forma, fazer da vontade a grande redentora capaz de transformar todo "Foi!" em um "Assim eu quis!” (Z, II, Da redenção).

É evidente na obra de Nietzsche e nas colocações acima o distanciamento do pensador com o modelo clínico moderno no que tange à objetividade, ao equilíbrio e à normalidade. Assim, resta-nos perguntar: que saúde seria possível de se produzir a partir da combinação do método genealógico e do pensamento trágico, diante da afirmação da importância e da singularidade da experiência do sofrimento para a existência, bem como do desequilíbrio e da inconstância da vida? Nietzsche apresenta o conceito de grande saúde (GC, §382), sem a qual não poderia produzir sua própria obra e sua existência, sem a qual não poderia exercitar a transvaloração de todos os valores. Ao longo de sua obra, em especial dentro dos prefácios posteriores de seus livros publicados em vida, a grande saúde aparece como a necessária experimentação de diversas saúdes, habitação dos vales e dos picos das vivências a fim de avaliar as variações das intensidades do viver, bem como os pensamentos e conceitos que 
povoam, no mesmo corpo, os estados de fraqueza e força. Assim, a partir da afirmação desta oscilação própria da existência, poder-se-ia entrar em contato com a grande razão, com o corpo e, através desta experimentação, elencar para si o que é bom e o que é ruim, o que é alto e o que é baixo na própria experiência da existência, no pensamento e na filosofia de um corpo.

Seria possível, através da oscilação e da convalescença da qual o exercício da grande saúde procederia, a possibilidade de avaliação dos próprios valores e sentidos que um corpo produz. Por meio da oscilação da própria saúde debilitada, Nietzsche, segundo ele próprio (EH, Por que sou tão sábio, §6), teria sido capaz de avaliar quais de seus pensamentos e conceitos teriam sido os mais salutares, quais aqueles que se mantinham firmes e bons, consistentes e condizentes com a afirmação da vida, mesmo quando esta habitava seus vales mais nefastos, doentes e tristes. Assim, o pensamento trágico não poderia dispensar, para Nietzsche, uma metodologia genealógica, nem o exercício de uma grande saúde. Compreendendo estes dois conceitos como fundamentais para a constituição crítica de uma saúde singular no autor, passamos a refletir como, para além da saúde dos povos e dos sistemas morais destes, o pensador trágico teria sido capaz de produzir uma autogenealogia a partir do exercício de uma grade saúde, isto é, processo pelo qual o filósofo não apenas torceria o modelo clínico moderno em sua compreensão da saúde e da doença, como voltaria tal exercício em direção a uma transvaloração dos valores de si e de suas vivências.

\section{Autogenealogia, transvaloração de todos os valores e conclusões}

O conceito de autogenealogia, como desenvolvido por pesquisadores da obra de Nietzsche, como Viesenteiner (2010) e Paschoal (2015), parece-nos uma interessante porta de entrada para se pensar a aproximação da transvaloração de todos os valores com um trabalho clínico dentro do pensamento nietzschiano. Apoiamos o argumento da prática autogenealógica como o pensamento genealógico voltado para o horizonte subjetivante, tendo como principal exemplo a reavaliação e reinterpretação dos valores que Nietzsche nos forneceria ao longo do livro autogenealógico Ecce homo e dos prefácios tardios de sua obra. Vemos como este elemento é imprescindível para que Nietzsche trabalhe, circunscreva e compreenda uma ética, um exercício de cuidado de si (EH, Por que sou tão inteligente, §2) e amarre no exercício de sua vida-pensamento os conceitos de amor fatti, eterno retorno, grande 
saúde e transvaloração de todos os valores, invertendo os valores do ideal ascético e sendo capaz de exercitar, como ele mesmo coloca, a transvaloração de todos os valores.

Em se justificando do por que afirmar Ecce homo como um estudo autogenealógico e não autobiográfico, em A genealogia da moral pode-se compreender que Nietzsche propõe uma superação dentro da cultura e dos valores e sentidos morais construídos ao longo de milênios pelo ideal ascético, e em Ecce homo pode-se ler a descrição de uma prática de reavaliação de seus próprios valores, sentidos, conceitos e perspectivas, e não de uma mera descrição narrativa e passivamente contemplativa dos mesmos. Tal reavaliação teria, então, desencadeado a possibilidade de Nietzsche (EH, Por que sou tão sábio, §1) perceber e inventar sua própria constituição como sujeito provindo dos valores e sentidos modernos, contaminados pelo ideal ascético e, num gesto de cuidado de si através da autogenealogia, reconhecer em suas vivências e em seu trabalho a operação da transvaloração de todos os valores, um processo que deflagra como se constitui um modo de existência singular e como, nessa constituição, a tarefa é lutar pela conquista de saúde que foi expressa, pelo autor, no exercício de superação da decadência de seu próprio tempo a favor de um tempo futuro.

É o exercício autogenealógico de avaliar os próprios valores que constitui Nietzsche como uma existência deslocada de seu próprio tempo, mesmo sendo fruto deste, e por meio do qual o autor pensa a importância da grande saúde que foi capaz de produzir ao longo da vida. Com o exercício de tal grande saúde, que, diferentemente de querer dizer de uma saúde estável e sempre sã, diz respeito a uma saúde que suporta e cria várias saúdes em um mesmo corpo, e tendo em vista a debilitada e oscilante disposição orgânica de Nietzsche ao longo da vida, o autor teria sido capaz de avaliar e identificar quais de seus pensamentos eram sadios e fortes, e quais seriam adoecidos e fracos. Ao viver os vales e picos de suas diversas saúdes com a mesma entrega, observação e convalescença, sem recusar, ressentir ou rechaçar a fraqueza e a doença, Nietzsche seria capaz de avaliar o valor de seus valores e o quanto eles afirmavam a vida e a existência, ao passar por penosos momentos onde o ressentimento pela vida poderia tomar conta de seu corpo por inteiro e não o fez (EH, Por que sou tão sábio, §6).

Ao experienciar o exercício de uma grande saúde afirmando a vida em suas intermitências e oscilações, Nietzsche teria sido capaz de vivenciar e compor os compassos éticos de sua obra afirmativa em relação à existência, isto é, o eterno retorno e o amor fatti (EH, Por que sou tão inteligente, §10). Para o autor, seu cuidado para não conduzir suas forças para o ressentimento quando doente, que seria o fruto e a etiologia de qualquer forma 
de adoecimento do corpo, foi seu cuidado e seu exercício para consigo, e a oportunidade não só de avaliar os valores da própria vida, mas também as bases e fundações do ideal ascético, do seu próprio ressentimento, da sua vontade de vingança para com a própria existência. É, como avaliado por Nietzsche em Ecce homo (EH, Por que sou tão inteligente, §9), através do exercício de uma grande saúde e de uma dietética específica em que hábitos, alimentações, estratégias e combates ao ressentimento seriam travados, que o autor teria sido capaz de transvalorar os valores do ideal ascético e da modernidade decadente, e compor a vida, o pensamento e a obra que não visam curar tal forma de existência do homem, mas sim superála.

O conceito de autogenealogia e a indicação desse exercício de cuidado por parte do próprio Nietzsche nos parecem passíveis de e interessantes para se produzir uma intercessão com o trabalho analítico proposto pela psicanálise, bem como pelos trabalhos que se remetem à produção de subjetividade no contemporâneo, onde o sujeito da clínica se vê diante de um exercício de criação de novas avaliações e interpretações para suas próprias vivências, no qual também o socius, a cultura, o que nos cerca antes e durante o exercício de pensar e existir, está presente na constituição desse modo de existência. Entretanto, diferentemente da análise como proposta por Freud, a autogenealogia não se ampararia em preceitos morais metafísicos que se baseariam no equilíbrio (como o princípio de constância) e na normalidade (como na estruturação do complexo edipiano ou em uma média estatística das populações) para funcionar. Sem tais preceitos morais metafísicos de orientação ao exercício de reavaliação e reinterpretação das vivências, não haveria possibilidade de constituir uma objetividade a respeito do sofrimento alheio.

Em lugar de tais preconceitos morais, que seriam expressões da vontade de verdade e signos do ideal ascético, a autogenealogia permitiria a produção de avaliações e interpretações sobre as próprias vivências a partir da vida como problema e do mistério da existência. Tratarse-ia, portanto, de um exercício de produção da própria subjetividade através da afirmação da vida no que ela teria de mais confuso e problemático e através do combate do ressentimento na vontade. Ao invés do preconceito estático do equilíbrio, a possibilidade de compreender o desequilíbrio, a inconstância da vida e o sofrimento como elementos necessários para a transformação e a superação dos corpos em vida. Ao invés de paramentar uma avaliação e uma interpretação de si a partir de critérios de normalidade dentro de uma população estatística, compreender a singularidade e o perspectivismo que evolveria cada ação e cada 
vivência. Por fim, em lugar de se orientar dentro do exercício de autoavaliação e autointerpretação a partir de parâmetros de objetividade entregues a sujeitos que saberiam de antemão sobre as vivências dos outros, produzir relações de amizade onde a partilha da alegria, como aponta Nietzsche (GC, §338), respeite o sofrimento entre as partes envolvidas e auxilie a cada uma destas a crescer e se superar a partir destes encontros.

O presente trabalho não pretendeu esgotar ou limitar possíveis e diferentes conexões entre o pensamento de Friedrich Nietzsche e a atividade clínica. A partir da presente pesquisa, almejou-se produzir uma entrada possível para desenvolver um movimento de intercessão onde o fazer clínico tenha em vista uma prática livre dos preconceitos morais, que compreenda a condição de singularidade do sofrimento alheio e que enxergue no ser humano, com toda sua carga valorativa de ressentimento e decadência, algo a ser superado através da transvaloração dos valores, que compõe a vida e gera a alegria. Tal trabalho de lida com o sofrimento e com a vida teria à sua disposição o rico arcabouço conceitual que Nietzsche, sua vida e sua obra teriam nos oferecido.

\section{Referências}

DELEUZE, G. (1985) Os intercessores. In: DELEUZE, G. Conversações: 1972-1990. Rio de Janeiro: Ed. 34, 1992.

FOUCAULT, M. História da loucura na idade clássica. 10. ed. São Paulo: Perspectiva, 2014. . As palavras e as coisas: uma arqueologia das ciências humanas. São Paulo: Martins Fontes, 1966.

. O nascimento da clínica. 6. ed. Rio de Janeiro: Forense Universitária, 2004.

. O poder psiquiátrico: curso dado no Collège de France, 1973-1974. São Paulo: Martins Fontes, 2006.

FREUD, S. (1900). A Interpretação de Sonhos. Rio de Janeiro: Imago, 2001.

FREUD, S. (1920). Além do princípio do prazer. In: FREUD, S. Edição standard brasileira das obras psicológicas completas de Sigmund Freud. v. 18. Rio de Janeiro: Imago, 1990, p. 13-74.

NIETZSCHE, F. W. Além do bem e do mal: preludio a uma filosofia do futuro. São Paulo: Companhia das Letras, 1992.

. A genealogia da moral. São Paulo: Companhia das Letras, 2013.

. Assim falou Zaratustra: um livro para todos e para ninguém. São Paulo: Companhia das Letras, 2011305

. A Gaia Ciência, São Paulo: Companhia das Letras, 2012. 
Ecce homo: como alguém se torna o que é. São Paulo: Companhia das Letras, 1999.

PASCHOAL, A. E. Autogenealogia: acerca do "tornar-se que se é". Dissertatio. Pelotas, v. 42, p. 27-44, 2015.

VIESENTEINER, J. L. Erlebnis (vivência): autobiografia ou autogenealogia? Sobre a "crítica da "razão da minha vida"' em Nietzsche. Estudos Nietzsche. Curitiba, v.1, n. 2, p. 327353, jul,/dez. 2010.

Yan Menezes Oliveira Mestre em Psicologia Institucional pela Universidade Federal do Espírito Santo E-mail: yan_menezes@hotmail.com

Karina Acosta Camargo Doutoranda e Mestra em Psicologia Clínica pela Pontíficia Universidade Católica de São

Paulo

E-mail: karina.jyoti@gmail.com

\footnotetext{
${ }^{1}$ É importante frisar que a partir da conceituação de vontade como vontade de poder, Nietzsche não pensa a vontade como uma unidade hermética, centralizadora e uniforme que conduziria a vida de um corpo, mas, sim, pensa a vontade como algo múltiplo e conflituoso, um jogo de forças que não afirmaria a vida, ou a própria vontade em si, mas, sim, a potência. Como Nietzsche faz Zaratustra dizer sobre o querer: "Somente onde há vida, há também vontade: mas não vontade de vida, e sim - assim vos ensino - vontade de potência”. (Z, II, Da superação de si).
} 